\title{
Phase structure of radar stratigraphic horizons within Antarctic firn
}

\author{
Steven A. ARCONE, ${ }^{1}$ Vandy B. SPIKES, ${ }^{2}$ Gordon S. HAMILTON ${ }^{3}$ \\ ${ }^{1}$ US Army Cold Regions Research and Engineering Laboratory, 72 Lyme Road, Hanover, NH, 03755-1290, USA \\ E-mail: Steven.A.Arcone@erdc.usace.army.mil \\ ${ }^{2}$ Earth Science Agency, LLC, Stateline, NV 89449, USA \\ ${ }^{3}$ Climate Change Institute, University of Maine, 303 Bryand Global Sciences Center, Orono, ME 04469-5790, USA
}

\begin{abstract}
We have recorded reflection profiles of firn through large areas of West Antarctica and part of the East Antarctic plateau using $400 \mathrm{MHz}$ short-pulse radar. The locations show accumulation rates that vary from well above to well below the vertical radar resolution. Most reflection horizons have extensive lateral continuity, and are composed of distinctive wavelets with a consistent phase polarity sequence within their successive half-cycles. We modeled these waveforms, and conclude that they arise from thin, double layers of ice over hoar, which is consistent with the standard model of firn stratification. In addition, we conclude that ice/hoar layers are extensive throughout West Antarctica and also present (although more sparsely) beneath the Antarctic Plateau.
\end{abstract}

\section{INTRODUCTION}

The stratigraphy of firn revealed in snow pits, trenches and ice cores shows density layering on the scale of centimeters (Gow, 1965, 1968; Benson, 1971; Cameron, 1971; Alley, 1988; Braaten, 2000). This observation appears to be consistent with the constant interference pattern of reflections at short-pulse ground-penetrating radar (GPR) pulse center frequencies of about $200 \mathrm{MHz}$ and below (Vaughan and others, 1999). However, at the higher GPR frequency of $400 \mathrm{MHz}$, many reflections are solitary wavelets, even though the layer resolution of the predominantly 1.5-cycle pulse is still about 0.35-0.42 $\mathrm{m}$ in firn (Arcone, 2002; Arcone and others, 2004). By solitary we mean that the peak values of the 1.5 cycles are at least $3 \mathrm{~dB}$ above the nearest half-cycles. Similarly, distinct reflection horizons have been observed in Greenland firn with higher-frequency spread spectrum radars (Kanagaratnam and others, 2001), although these radars do not have a pulse duration equivalent to a comparably small number of cycles.

Based on calculations of reflectivity strength, the sensitivity of GPR to thin layers, profile amplitude structure, and the widespread occurrence of hoar events in polar regions, Arcone and others (2004) have argued that these GPR events may be related to single (or clusters of) thin layers of ice (Gow, 1968). In polar regions, these ice layers are usually generated by condensing evaporation from underlying layers of hoar, as per the standard model of firn stratification (Alley, 1988). Arcone and others (2004) mainly discussed the lateral continuity and waveform of only two GPR events, so it is not clear that their model of a thin layer of ice is consistent with all reflection events. In this paper, we examine the waveforms of many events recorded at several Antarctic locations to determine if they show a consistent pattern and contain more information regarding their origin.

Our objective is to test the hypothesis that these solitary GPR waveforms should be consistent in structure given that they are generated by the classic model of firn stratification for Antarctica. By structure, we mean the relative amplitudes, and the phase polarity sequence of the major halfcycles of the pulse (Arcone and others, 1995; Arcone, 1996). By consistency we mean both from event to event, and along the same event horizon. We test this hypothesis by examining the phase polarity sequence of the strongest halfcycles of many $400 \mathrm{MHz}$ wavelets we recorded at several locations throughout West Antarctica and near the South Pole during the 4 year International Trans-Antarctic Scientific Expedition (ITASE) program (Mayewski, 2003). We include two locations near ice divides where accumulation rates appear to exceed the vertical resolution of the radar, and two where the rates do not, to give greater perspective to our study.

\section{LOCATION}

Figure 1 locates the ITASE transects, ice-coring sites and ice divides. We examine our waveforms from profile segments recorded near the labeled core sites. Core site 99-2 is at the end of transect II (recorded in 1999), which encounters hilly topography and significantly variable accumulation rates. Core sites 00-2 to 00-4 lie along the part of transect II (recorded in 2000) that is near an ice divide. Spikes and others (2004) have tracked radar horizons between core sites 00-4 and 00-5 to show that they are isochronal. We track two of these horizons and use the dating of Kaspari and others (2004) to find an average accumulation rate at 00-2 because this core had not been processed as of this writing. This site appears to have the highest accumulation rate. Core site 01-4 (recorded in 2001) along transect III is also near an ice divide. The South Pole site (SPS) is about $5 \mathrm{~km}$ from South Pole Station. Surface conditions along all transects were generally smooth with few sastrugi.

\section{EQUIPMENT, WAVELET CHARACTERISTICS AND DATA PROCESSING}

We used a Geophysical Survey Systems Inc. (GSSI) model SIR 10B control unit and towed a GSSI $400 \mathrm{MHz}$ (model 5103) antenna transducer unit in a small sled. The $4.1 \mathrm{~ns}$ (Fig. 2) duration of the major 1.5 cycles of the pulse provides about $0.41 \mathrm{~m}$ interface resolution in firn of refractive index $n=1.5$ (density: $\rho=600 \mathrm{~kg} \mathrm{~m}^{-3}$ ). The profiles contain 16-bit traces at 8192 samples per trace. All profiles were recorded with 


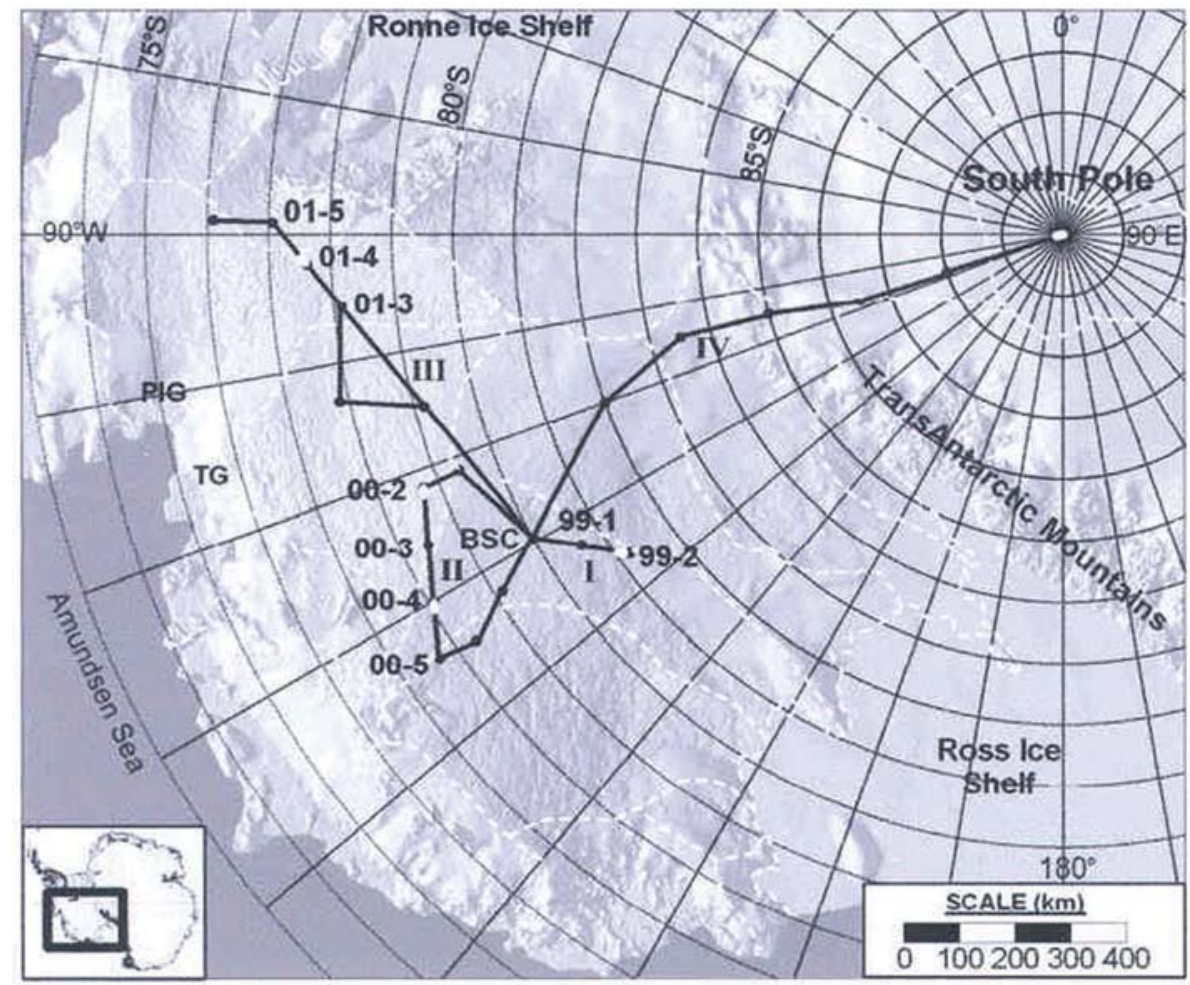

Fig. 1. Location of the ITASE transects, core sites cited in the text, and major divides (dashed lines; after Liu and others, 1999) between drainage basins of West Antarctica. I, II, III and IV refer to the transects during 1999-2002, respectively. Transect portions for the profiles discussed are indicated by thicker, white segments.

the same control system antennas, and filter settings, and all had their range gain removed before post-processing. We then applied bandpass filtering $(150-550 \mathrm{MHz})$ to reduce high- and low-frequency noise, and removed constant timedelay clutter with a wide $(300$ traces $=3 \mathrm{~km}$ ) horizontal filter. The profiles are displayed in line intensity, rather than a wiggle trace format, to show the consistent waveform phase structure with distance. The profiles are not corrected for elevation, so that the spatial changes of accumulation rates relative to the surface can be seen more easily.

We used known calibrations between dielectric permittivity, $\varepsilon$, and snow density (Cumming, 1952; Kovacs and others, 1996) and the simple echo delay formula $d=\mathrm{ct} / 2 n$ to transform echo time delay, $t$, into depth, $d$, where $c=0.3 \mathrm{~m} \mathrm{~ns}^{-1}$ and $n=\sqrt{\varepsilon}$. We performed our depth calibration meter by meter, based on the $1 \mathrm{~m}$ increment density profiles measured at each core site. We combined the density profiles and depth vs time calibrations to calibrate cumulative water equivalent (w.e.) against event time delay.

The antenna radiates a wide beam, outside of which the complexities of the directivity (Arcone, 1995) are unimportant because of the gentle slope of the layers. We used a running, 32-fold stack to give an effective spatial recording rate of about 1 trace per $2.7 \mathrm{~m}$ at an average traverse speed of $2 \mathrm{~m} \mathrm{~s}^{-1}$ for transect I, about 1 trace per $15 \mathrm{~m}$ at the $3.3 \mathrm{~m} \mathrm{~s}^{-1}$ average speed of transects II and III, and about 1 trace per $12 \mathrm{~m}$ at the $2.5 \mathrm{~m} \mathrm{~s}^{-1}$ speed of transect IV. The additional stacking that we used to provide average wavelet characteristics, discussed later, gives an effective lateral resolution at least 12 times less than these values, and precludes any need to consider Fresnel zone widths for antenna sensitivity. At our highest compression, one trace represents about $60 \mathrm{~m}$ of distance traveled. We simultaneously recorded precise geodetic differential global positioning system (GPS) data to locate our position and elevation.

\section{RESULTS}

\section{Profile 00-4 to 00-2 and core site 00-2}

We show the profiles from core sites 00-4 to 00-3 and from 00-3 to 00-2 in Figure 3. The depths of the cores were 58.4,

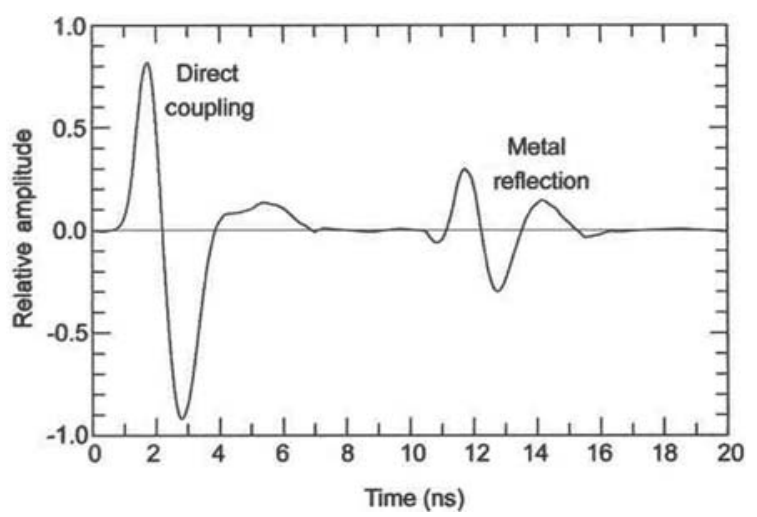

Fig. 2. The $400 \mathrm{MHz}$ antenna wavelet form, as revealed by a reflection from a metal sheet buried in firn $(\varepsilon=1.7)$. Consequently, the +-+ phase polarity sequence (red-blue-red in the profiles) for the major half-cycles is the inverse of that of the wavelet transmitted into the firn. The direct coupling is through the small air gap between the transmitter and receiver antennas. The bandpass filtering applied to this trace is the same as that applied to all profiles. 


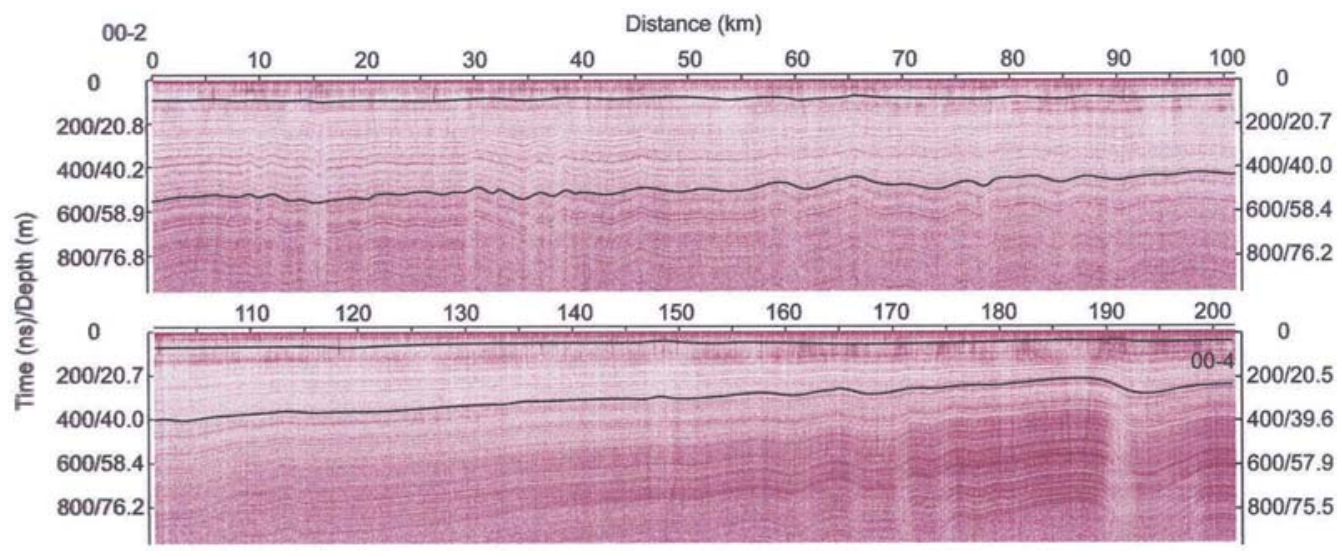

Fig. 3. The top $1000 \mathrm{~ns}$ (about $93 \mathrm{~m}$ ) of the year 2000 profile recorded from core site 00-2 (0 km) to 00-3 (101 km) to 00-4 (202 km). The upper and lower dark lines trace horizons that correspond with 1922 and 1991, respectively. The depth scales at 800 ns are estimates.

60.3 and $61.3 \mathrm{~m}$, respectively, with corresponding densities of 800,780 and $750 \mathrm{~kg} \mathrm{~m}^{-3}$. Thus, the firn-ice transition $\left(830 \mathrm{~kg} \mathrm{~m}^{-3}\right)$ was surely reached by the $800 \mathrm{~ns}(76 \mathrm{~m})$ depth of these profiles. Using the core at site 00-4, the average water accumulation rate between 1922 (266 ns round-trip delay) and 1991 (42 ns) was computed at $0.189 \mathrm{mw}^{\mathrm{e}}$. $\mathrm{a}^{-1}$ (Kaspari and others, 2004). We follow the horizons (associated with a particular half-cycle and not with the leading edge of a wavelet) at these time delays to site 00-2, where the stronger horizons are more widely spread and their wavelet structure is easier to discern. At site 00-2 the 1991 and 1922 horizons then occur at 93 ns (cumulative w.e. of $4.6 \mathrm{~m}$ from surface) and $553 \mathrm{~ns}$ (cumulative w.e. of $35.4 \mathrm{~m}$ from surface), respectively. Therefore, at site 00-2 the average yearly w.e. rate between the above years becomes about $0.45 \mathrm{~m} \mathrm{a}^{-1}$.

Figure 4 shows a highly stacked version of the first $6 \mathrm{~km}$ from site 00-2 that covers the first $600 \mathrm{~ns}$, or about $56 \mathrm{~m}$ of depth. Many of the relatively stronger horizons appear as solitary, 1.5 - to 2.5 -cycle wavelets. All wavelets circled in the figure have a dominant three half-cycles in which the peak amplitude is at least $3 \mathrm{~dB}$ above that of the nearest bands. The relative strengths and three- to five-band structure are most apparent in the detail of Figure 5, which also provides a Hilbert magnitude transform of a single trace to show the relative strengths of the energy envelopes of these events. In some cases in Figure 4, such as between 280 and $300 \mathrm{~ns}$, the wavelets are spaced too closely to resolve. Of 44 solitary wavelet events at site 00-2, 38 have a -+phase polarity sequence. This wavelet attribute is not characteristic of just the firn regime since it carries deeper than $70 \mathrm{~m}$ (Fig. 6).

Although the wavelet resolution is significantly less than the accumulation rate at $00-2$ (the w.e. rate of $0.45 \mathrm{~m} \mathrm{a}^{-1}$ at site $00-2$ translates to $0.75 \mathrm{~m} \mathrm{a}^{-1}$ of equivalent firn with density $600 \mathrm{~kg} \mathrm{~m}^{-3}$, and to $0.50 \mathrm{~m} \mathrm{a}^{-1}$ of equivalent ice), weaker signals between the stronger wavelets appear to provide a near continuum of events. These weaker signals must be primary events because the successive values of reflectivity for multiple reflections between layers would
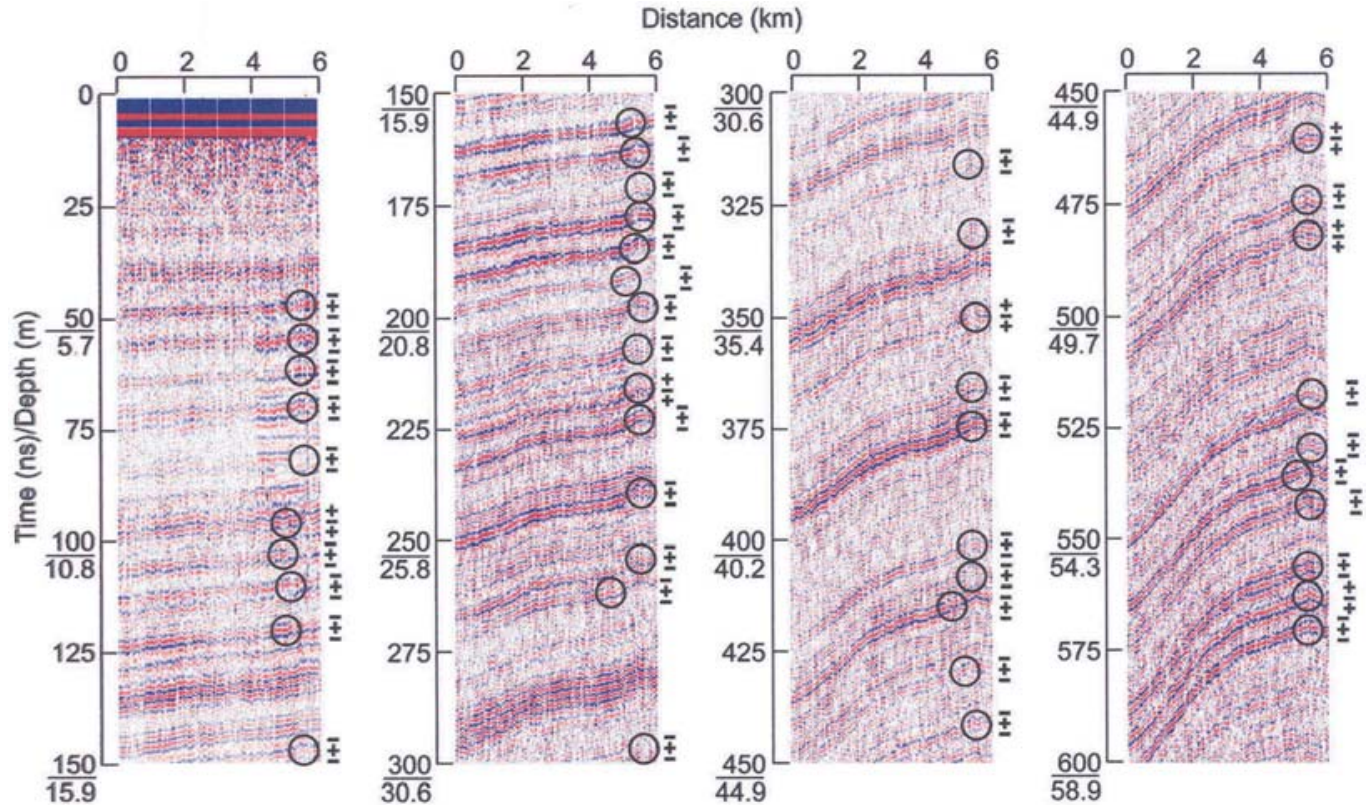

Fig. 4. The top $600 \mathrm{~ns}$ of the profile of the first $6 \mathrm{~km}$ from core site $00-2$. The circled events are wavelets distinguished by peak amplitudes that are at least $3 \mathrm{~dB}$ above those of the nearest events. 


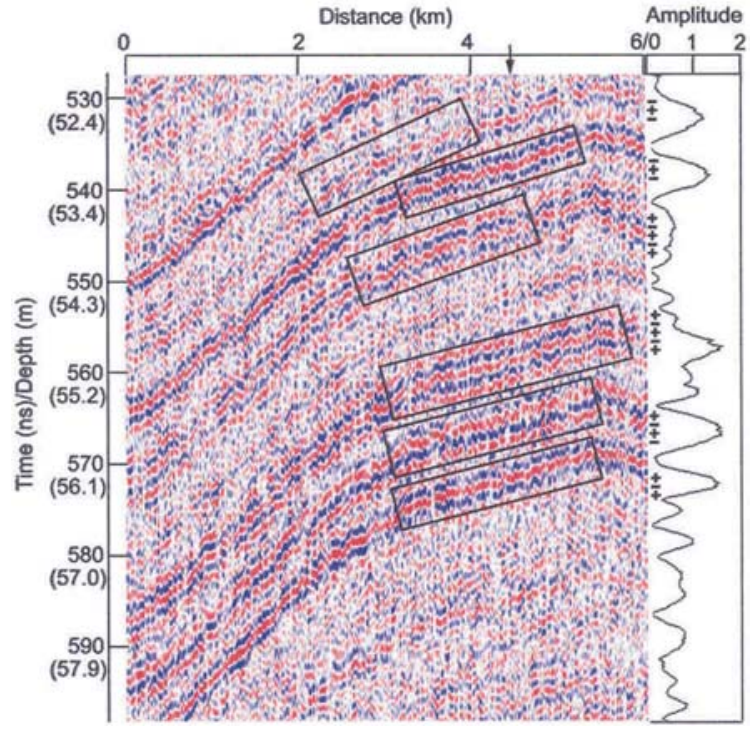

Fig. 5. Detail from Figure 4, and a Hilbert magnitude transformation of the trace located beneath the small arrow. The boxed sections highlight horizons with solitary wavelets. The detail shows that some events have the 2.5-cycle structure seen later in the modeling. The amplitude scale of the trace is relative. The energy envelopes of the transform rise as much as $9 \mathrm{~dB}$ above the noise level in the troughs.

provide $<-150 \mathrm{~dB}$ total reflectivity, which would be beyond detection by this radar. The 69 year span of 460 ns translates to an average of about $6.7 \mathrm{~ns} \mathrm{a}^{-1}$, or about 1.6 wavelets per year. Therefore, the number of primary events exceeds the number of years and so any possible annual signal is convolved within the continuum of events.

\section{Other sites}

Figure 7 shows a $6 \mathrm{~km}$ long profile recorded near SPS, where accumulation rates have been measured at only about $0.03-$ 0.04 mw.e. $\mathrm{a}^{-1}$ (Van der Veen and others, 1999). We calibrated depth from a density profile obtained in 1995

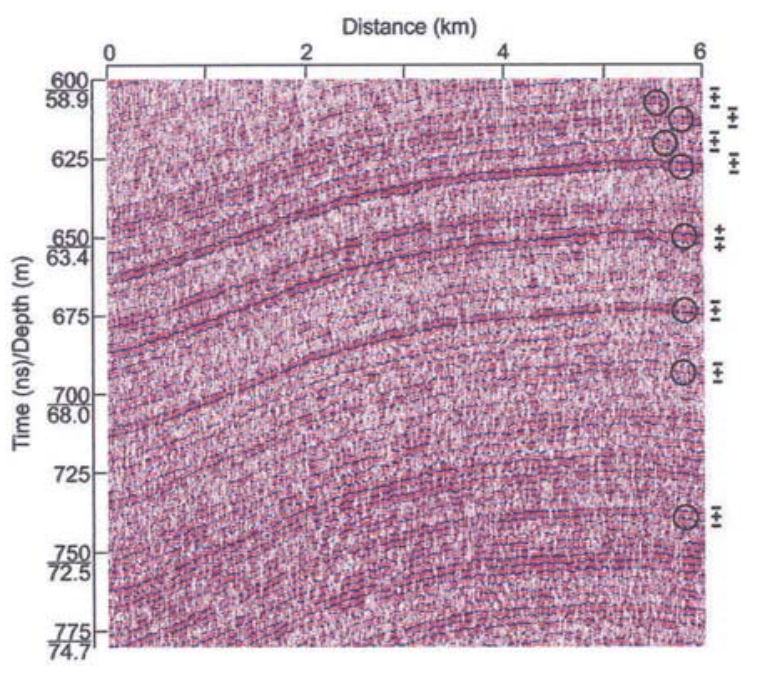

Fig. 6. Profile of the first $6 \mathrm{~km}$ from core site $00-2$ between 600 and $780 \mathrm{~ns}$.

(personal communication from D. Dixon, 2003), which showed the firn-ice transition at $118 \mathrm{~m}$ (about $1223 \mathrm{~ns}$ ) depth. Although the accumulation rates are far less than our GPR vertical resolution at any depth, the profile still shows solitary wavelets, the majority of which have the -+structure. The horizons are generally weaker than at the other sites, which is consistent with the likelihood of relatively weaker density contrasts because saturation vapor pressures depend on the absolute temperature of the snow (Albert and others, 2004; about $-50^{\circ} \mathrm{C}$ near South Pole, and about $-28^{\circ} \mathrm{C}$ near BSC). As with all the other sites, there is a continuum of wavelets, but there are only two deeper than about $56 \mathrm{~m}$ that are prominent enough for their phase to be read (Fig. 8). These events could be tracked for tens of kilometers as we approached SPS.

We investigated three additional sites, and all the results are summarized in Table 1. We chose sites where there was
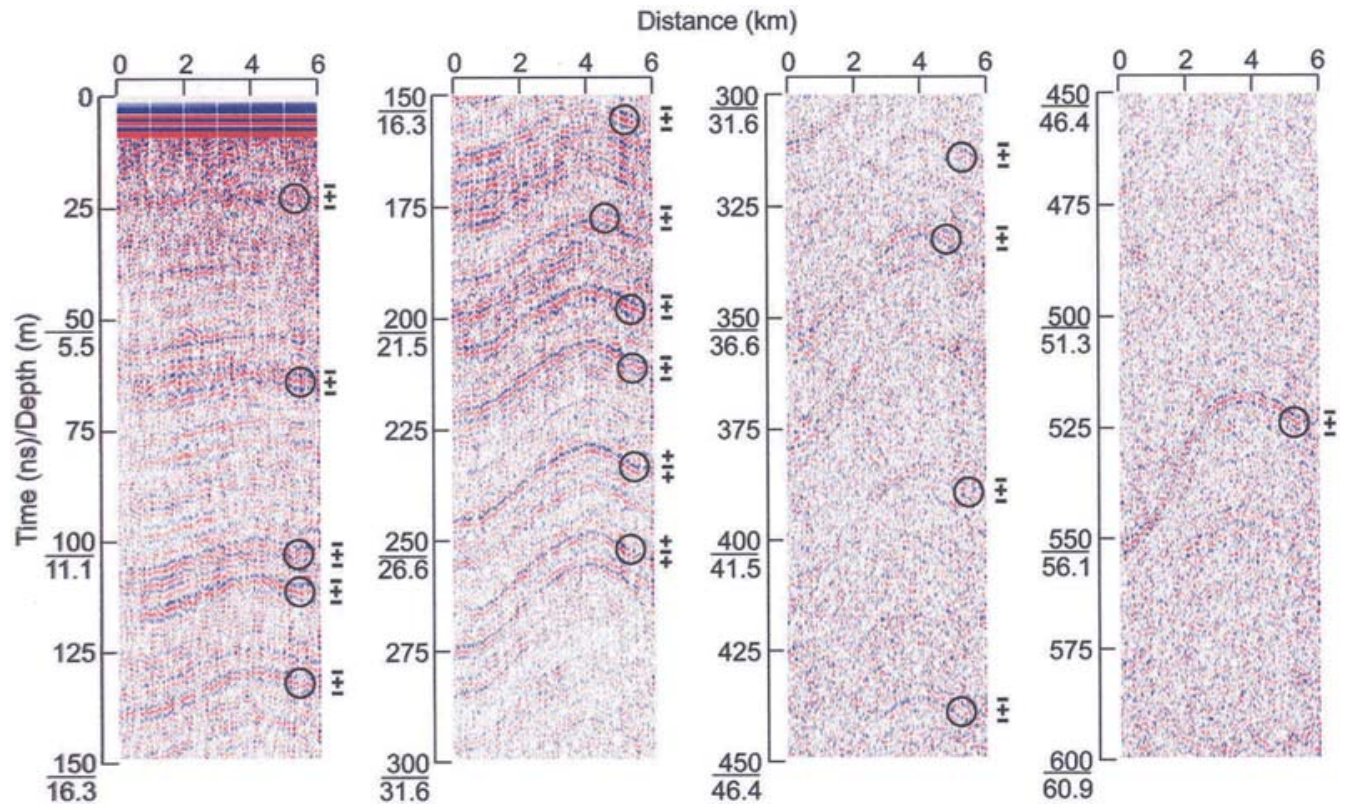

Fig. 7. The top $600 \mathrm{~ns}$ of the profile of the last $6 \mathrm{~km}$ before the South Pole Station site. The circled events are wavelets distinguished by their amplitudes. The depth scale is based on a density profile from within $100 \mathrm{~km}$ of South Pole Station. 


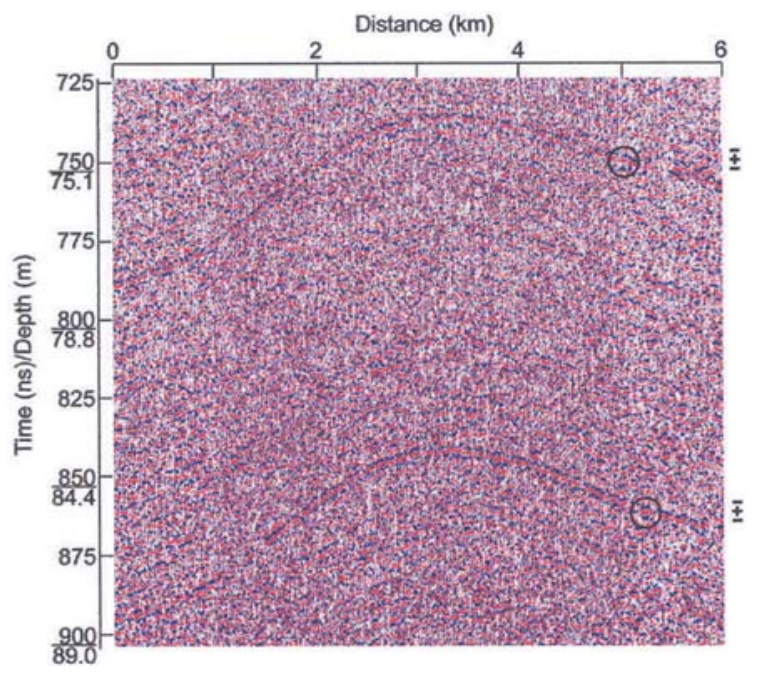

Fig. 8. Profile of the first $6 \mathrm{~km}$ from the South Pole Station site between 723 and $905 \mathrm{~ns}$. The display has been intensified to show the events better.

minimal dip in the strata so that the stacking process could fairly average the wavelets along the horizons and allow them to be easily viewed. The horizons near core site $00-4$ are not necessarily the same as those near site 00-2 because some have extinguished in between and some have newly generated. Those below about 375 ns at 00-4 become too close (or they interfere) for their phase polarity sequences to be determined. The profiles near core sites 01-4 and 00-2 showed the deepest horizons, some of which reached the bottom of the profiles at $135 \mathrm{~m}$ depth (Arcone, 2002). The core for site 01-4 has yet to be processed as of this writing, but cores at nearby sites 01-3 and 01-5 show accumulation rates of 0.33 and 0.34 m w.e. $\mathrm{a}^{-1}$ (Kaspari and others, 2004), respectively. The $01-5$ value is biased toward the low side because it is situated in an anticlinal stratigraphic structure where accumulation is decreased by topographic effects (Black and Budd, 1964). The $6 \mathrm{~km}$ segment we examined along the 1999 profile ends $4 \mathrm{~km}$ from core site 99-2. This core site showed an anomalously low accumulation rate, with the firn-ice transition occurring at only $37 \mathrm{~m}$ depth. The firn-ice transition within the segment we analyzed is interpreted from the stratigraphy to be about $5 \mathrm{~m}$ lower. In total, of 127 wavelets identified, $85 \%$ have the -+structure for the strongest three half-cycles.

\section{MODELING AND DISCUSSION}

The standard model of firn stratification, which is built on many observations (Gow, 1965, 1968; Alley, 1988), accounts for the frequent occurrence of thin ice layers ('crusts') about 1-2 $\mathrm{mm}$ thick (Arcone and others, 2004). The nearpurity of the ice was deduced by Gow (1968) from petrographic studies. These ice layers are generated by, and form above, a layer of low-density (relative to the firn matrix) hoar beneath. The permittivity structure of this double layer will therefore consist of a higher- $\varepsilon$ ice layer above a lower- $\varepsilon$ hoar layer, both embedded in a firn matrix whose $\varepsilon$ value is between those of the two. The interfaces defining these thin layers are too close to be resolved by a $400 \mathrm{MHz}$ pulse. Here, we perform modeling to determine how this double layer is consistent with the waveforms we
Table 1. Wavelet phase polarity sequences within first $600 \mathrm{~ns}$

\begin{tabular}{lcc}
\hline Site & Solitary wavelets & $\%-+-$ \\
\hline $00-2(0-6 \mathrm{~km}$ : east-west) & 44 & 86 \\
$00-4(0-6 \mathrm{~km}:$ east-west) & 18 & 78 \\
$01-4(0-6 \mathrm{~km}:$ west-east) & 31 & 87 \\
$99-2(167-173 \mathrm{~km})$ & 18 & 83 \\
Near South Pole Station & 16 & 88 \\
(last 6 km: north-south) & & \\
\hline
\end{tabular}

observe. As mentioned above, Arcone and others (2004) assumed the only density anomaly was that of ice, and failed to investigate any consistency in waveform. Our observations suggest that most of the waveforms are caused by a low-density thin layer, but these observations must be consistent with the presence of so many thin ice layers.

We interpret the phase polarity sequences from the results of a numerical exercise that computes reflections of a model of the waveform shown in Figure 2. The incident pulse, $E_{\mathrm{i}}(t)$, is an empirical fit to our transmitted waveform, and is determined by the function

$$
E_{\mathrm{i}}(t)=\sin ^{2}(\omega t / 6) \sin \omega(t+\pi / 4),
$$

which is the leading waveform shown in Figure 9a. It was synthesized from a Fourier series construction over a bandwidth of $5-50000 \mathrm{MHz}$. The quantity $\omega$ is the radian equivalent of $400 \mathrm{MHz}$, and the expression is modulated by step functions that allow 2.5 cycles. The waveform shows the same dominant, central three half-cycles, the correct sequence of relative amplitude strengths, and the weaker leading and trailing half-cycles of the reflection in Figure 2.

The reflected waveforms $E_{\mathrm{r}}(t)$, were Fourier synthesized from a triple summation such that

$$
E_{\mathrm{r}}(t)=\Sigma_{\mathrm{i}} E_{\mathrm{i}}\left(\omega_{\mathrm{i}}\right) \times \Sigma_{p} R_{p} \times \Sigma_{m p} T_{m p} \exp \left(-i 2 k_{\mathrm{i}} d_{m p} n_{m p}\right) .
$$

The first summation is over the spectrum of the Fourier series for the expression in Equation (1). The second summation is for the Fresnel electric field reflection coefficient, $R_{p}$, of each of $p$ successive interfaces. The third accounts for the two-way electric field transmission coefficients between the successive interfaces between the firn above $(m)$ and the firn below $(p)$ leading to $R_{p}$. The exponential function accounts for the two-way phase delay within the successive layers of thickness $d_{m p}$ leading to interface $p$. The quantity $k=\omega / c$ is the free-space propagation wavenumber and $n_{m p}$ is the refractive index of the individual layers. Only primary reflections are considered. Although secondary reflection coefficients are infinite in number, their summation insignificantly affects $E_{\mathrm{r}}(\omega)$. Accurate amplitudes were computed for the $1 \mathrm{~mm}$ layers because the upper bandwidth of $50000 \mathrm{MHz}$ insures a large phase delay within them.

The leading, transmitted waveform in Figure 9a (event 1) shows a +-+ phase polarity sequence for the successive half-cycles, as appropriate for an interface between a high- $\varepsilon$ material (firn at $800 \mathrm{~kg} \mathrm{~m}^{-3}$ ) situated below it, and a low- $\varepsilon$ material (firn at $750 \mathrm{~kg} \mathrm{~m}^{-3}$ ) above. Waveform 2 of Figure 9a is a reflection of the transmitted waveform from a $6 \mathrm{~mm}$ layer of low- $\varepsilon$ firn $\left(500 \mathrm{~kg} \mathrm{~m}^{-3}\right)$ embedded within the $800 \mathrm{~kg} \mathrm{~m}^{-3}$ firn. This -+- waveform is almost an inversion of the transmitted form, except that the relative amplitudes in the 

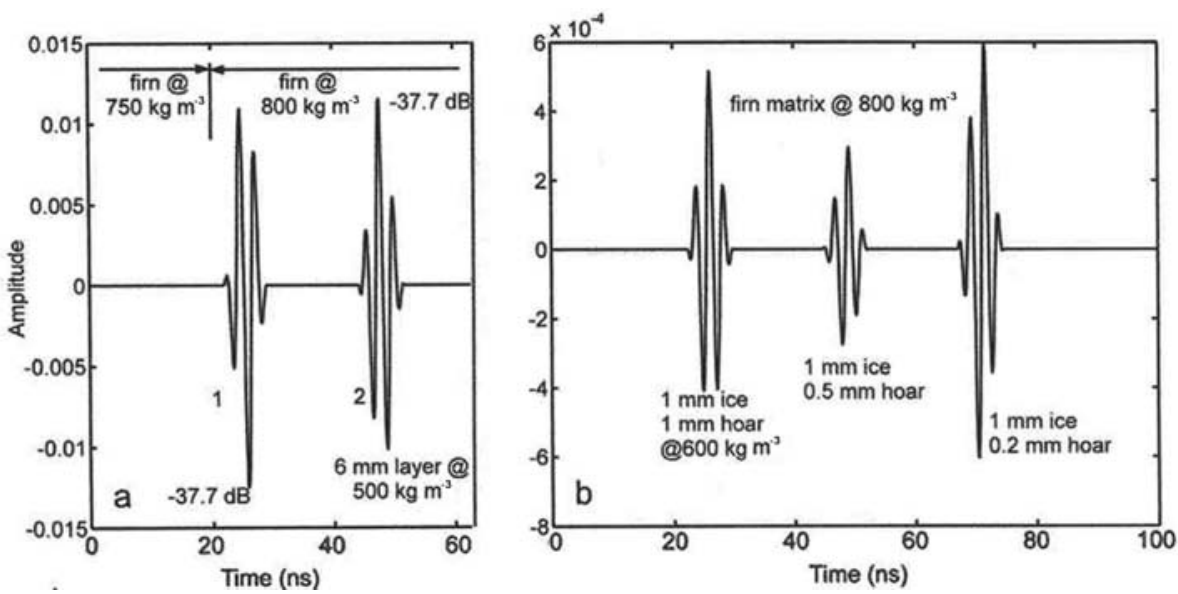

Fig. 9. Theoretical model of (a) our wavelet (event 1) and its reflection from a $6 \mathrm{~mm}$ layer of hoar (event 2), and (b) reflections from various thin, double-layer structures of ice over hoar. In (a) wavelet 1 reflects from the interface between firn at $750 \mathrm{~kg} \mathrm{~m}^{-3}$ above and at $800 \mathrm{~kg} \mathrm{~m}^{-3}$ below. The peak values of the wavelets relative to a reflection from a perfect reflector are indicated in $\mathrm{dB}$, and density values are given for the hoar and firn matrix. In (b) the structure of three, strong, central half-cycles with the -+- phase structure evolves when the hoar layer thickness becomes comparable to, and then thicker than, the ice layer.

sequence of half-cycles are reversed. The layer thickness and density parameters were chosen to give the same peak amplitudes for the two waveforms. The central three halfcycles dominate in amplitude and so thin-layer reflections are very similar in form to those from single interfaces.

In Figure $9 \mathrm{~b}$ we show waveforms reflected from successively thicker layers of hoar (from 0.2 to $1 \mathrm{~mm}$ ), all underlying the same thickness of ice. As long as the hoar layer thickness compares with, or is thicker than, that of the ice layer, as observed naturally, the -+- waveform results with weaker, leading and trailing half-cycles to give a 2.5cycle length. For thinner layers of hoar there are four strong half-cycles in a +-+- sequence. Additionally, even a sequence of such double layers with sufficient hoar thicknesses will produce the -+- waveform (Fig. 10), so long as the total thickness of the sequence does not exceed about $10 \mathrm{~cm}$.

The example of Figure $9 b$ gives about the minimum detectable thicknesses (the strongest reflectivity here is about $-64 \mathrm{~dB}$ ) given the performance figure (about $120 \mathrm{~dB}$ ) and usable dynamic range (about $90 \mathrm{~dB}$ ) of our radar system. It only takes an increased hoar thickness of 3-20 mm to bring the earliest signal in this model into the measured reflectivity range of -25 to $-50 \mathrm{~dB}$ (Arcone and others, 2004).

The increase of horizon strength with distance to the northwest in Figure 3 appears to be consistent with our previous interpretation (Arcone and others, 2004) that these stronger events result from clusters of thin layers, as modeled in Figure 10, and not from a single thin layer. As accumulation rates decrease, these couplets should become closer and increase the composite layer reflectivity. Therefore, we consider the decreased amplitude of horizons near SPS to result mainly from less contrast between the density of the hoar and the firn matrix than might occur at the more northerly locations (the ice and the firn matrix should not show any different density values) because of decreased vapor pressure at colder temperatures, as explained above.
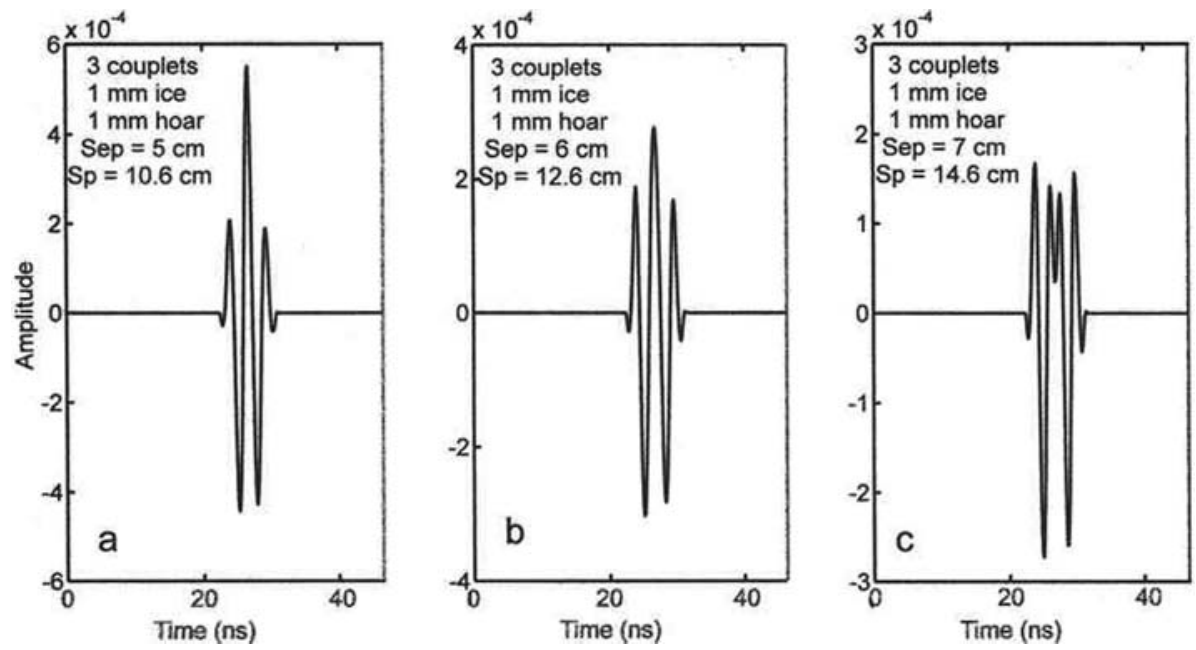

Fig. 10. Theoretical reflections from three couplets of ice over hoar, with each couplet separated by $5 \mathrm{~cm}(\mathrm{a}), 6 \mathrm{~cm}$ (b) and $7 \mathrm{~cm}(\mathrm{c})$. The densities of the hoar and firn are the same as those given in Figure 9. The -+- wavelet structure holds for the three couplets so long as their total span (Sp) does not exceed about 10-11 cm. The peak amplitudes increase with decreasing separation between the couplets. 


\section{CONCLUSIONS}

Our interpretation of double layers for the solitary events suggests that ice/hoar is a common formation throughout the year at any location and detectable at all depths within firn. This is consistent with all ITASE cores examined to date, with previous cores (Gow, 1968) and with the standard model of firn stratification. Hoar events that occur over days can thus serve as accurate time markers in the records. Their existence near South Pole suggests that they commonly occur throughout East Antarctica as well, which is consistent with observations that the same stratification processes occur there (Albert and others, 2004). The deepest layers we have recorded are at about $135 \mathrm{~m}$ (Arcone, 2002), which is well below the firn-ice transition but also about where the signal is lost to noise. Despite the densification that occurs with depth, the events at these depths imply that the hoar layers maintain their relatively lower density and their relatively greater thicknesses with respect to the ice layers well below the firn-ice transition.

Our modeling shows that it is mainly the fluctuation of hoar thickness that determines the phase of a wavelet because ice layers are generally very thin, and that it is not possible to resolve ice-hoar couplets within about a $10 \mathrm{~cm}$ span. These facts, and the numerous ice layers seen in the ITASE cores (Arcone and others, 2004), suggest that the stronger events represent clusters of couplets with thicker layers of hoar. The continuum of weak and strong events in the records suggests that hoar and ice formation is a nearly continuous process during times of accumulation. Indeed, the average of 1.6 wavelets per year at site $00-2$, where accumulation rates exceeded the wavelet resolution, precludes the possibility that these events are only annual signals.

\section{ACKNOWLEDGEMENTS}

US National Science Foundation awards 9814589 and 00880355 (to S.A.A.) supported this work. We thank J. Palais for her support, our fellow ITASE members P. Mayewski and D. Dixon for supplying ice-core data, and two reviewers and the editor for helpful comments.

\section{REFERENCES}

Albert, M., C. Shuman, Z. Courville, R. Bauer, M. Fahnestock and T. Scambos. 2004. Extreme firn metamorphism: impact of decades of vapor transport on near-surface firn at a lowaccumulation glazed site on the East Antarctic plateau. Ann. Glaciol., 39, 73-78.

Alley, R.B. 1988. Concerning the deposition and diagenesis of strata in polar firn. J. Glaciol., 34(118), 283-290.

Arcone, S.A. 1995. Numerical studies of the radiation patterns of resistively loaded dipoles. J. Appl. Geophys., 33(1-3), 39-52.
Arcone, S.A. 1996. High resolution of glacial ice stratigraphy: a ground-penetrating radar study of Pegasus Runway, McMurdo Station, Antarctica. Geophysics, 61(6), 1653-1663.

Arcone, S.A. 2002. Radar profiling at $1500 \mathrm{~ns}$ in firn. In Koppenjan, $\mathrm{S}$. and $\mathrm{H}$. Lee, eds. Proceedings of the Ninth International Conference on Ground-Penetrating Radar, Santa Barbara, California, USA, April 29-May 2, 2002. Bellingham, WA, International Society for Optical Engineering.

Arcone, S.A., D.E. Lawson and A.J. Delaney. 1995. Short-pulse radar wavelet recovery and resolution of dielectric contrasts within englacial and basal ice of Matanuska Glacier, Alaska, U.S.A. J. Glaciol., 41(137), 68-86.

Arcone, S.A., V.B. Spikes, G.S. Hamilton and P.A. Mayewski. 2004. Stratigraphic continuity in 400-MHz short-pulse radar profiles of firn in West Antarctica. Ann. Glaciol., 39, 195-200.

Benson, C.S. 1971. Stratigraphic studies in the snow at Byrd Station, Antarctica, compared with similar studies in Greenland. In Crary, A.P., ed. Antarctic snow and ice studies II. Washington, DC, American Geophysical Union, 333-353. (Antarctic Research Series 16.)

Black, H.P. and W. Budd. 1964. Accumulation in the region of Wilkes, Wilkes Land, Antarctica. J. Glaciol., 5(37), 3-15.

Braaten, D.A. 2000. Direct measurements of episodic snow accumulation on the Antarctic polar plateau. J. Geophys. Res., 105(D8), 10,119-10,128.

Cameron, R.L. 1971. Glaciological studies at Byrd Station, Antarctica, 1963-1965. In Crary, A.P., ed. Antarctic snow and ice studies II. Washington, DC, American Geophysical Union, 317-332. (Antarctic Research Series 16.)

Cumming, W.A. 1952. The dielectric properties of ice and snow at 3.2 centimeters. J. Appl. Phys, 23(7), 768-773.

Gow, A.J. 1965. Snow studies in Antarctica. CRREL Res. Rep. 177.

Gow, A.J. 1968. Deep core studies of the accumulation and densification of snow at Byrd Station and Little America V, Antarctica. CRREL Res. Rep. 197.

Kanagaratnam, P., S. Gogineni, N. Gundestrup and L. Larsen. 2001. High-resolution radar mapping of internal layers at NGRIP. J. Geophys. Res., 106(D24), 33,799-33,811.

Kaspari, S. and 6 others. 2004. Climate variability in West Antarctica derived from annual accumulation rate records from ITASE firn/ice cores. Ann. Glaciol., 39, 585-594.

Kovacs, A., A.J. Gow and R.M. Morey. 1996. The in-situ dielectric constant of polar firn revisited. Cold Reg. Sci. Technol., 23(3), 245-256.

Liu, H., K.C. Jezek and B. Li. 1999. Development of an Antarctic digital elevation model by integrating cartographic and remotely sensed data: a geographic information system based approach. J. Geophys. Res., 104(B10), 23,199-23,213.

Mayewski, P.A. 2003. Antarctic oversnow traverse-based Southern Hemisphere climate reconstruction. Eos, 84(22), 205, 210.

Spikes, V.B., G.S. Hamilton, S.A. Arcone, S. Kaspari and P. Mayewski. 2004. Variability in accumulation rates from GPR profiling on the West Antarctic plateau. Ann. Glaciol., 39, 238-244.

Van der Veen, C.J., E. Mosley-Thompson, A.J. Gow and B.G. Mark. 1999. Accumulation at South Pole: comparison of two 900-year records. J. Geophys. Res., 104(D24), 31,067-31,076.

Vaughan, D.G., H.F.J. Corr, C.S.M. Doake and E.D. Waddington. 1999. Distortion of isochronous layers in ice revealed by ground-penetrating radar. Nature, 398(6725), 323-326. 